\title{
Drug-Induced Nephropathy
}

National Cancer Institute

\section{Source}

National Cancer Institute. Drug-Induced Nephropathy. NCI Thesaurus. Code C114583.

Kidney damage resulting from exposure to drugs. 